\title{
Protective effect of 3-aminobenzamide, an inhibitor of poly (ADP-ribose) synthetase, against streptozotocin-induced diabetes
}

\author{
P. Masiello, T. Locci Cubeddu, G. Frosina and E. Bergamini \\ Istituto di Patologia Generale, University of Pisa, Pisa, Italy
}

\begin{abstract}
Summary. The addition of 3-aminobenzamide (a potent inhibitor of poly(ADP-ribose)synthetase) into the incubation medium, prevents streptozotocin-induced inhibition of glucosestimulated insulin release from isolated islets [control $142 \pm 14 \mu \mathrm{U} \cdot$ islet $^{-1} \cdot \mathrm{h}^{-1}$; streptozotocin $(0.5 \mathrm{mg} / \mathrm{ml}) 31 \pm 8$; 3 -aminobenzamide $(1.0 \mathrm{mg} / \mathrm{ml}) 96 \pm 11$; streptozotocin plus 3 -aminobenzamide $122 \pm 19$ ]. In vivo, intraperitoneal 3-aminobenzamide $300 \mathrm{mg} / \mathrm{kg}$ body weight prevents the appearance of overt diabetes in streptozotocin-treated rats. These protective effects of 3-aminobenzamide are dose-dependent and are similar to those exerted by nicotinamide. Taking into account
\end{abstract}

that poly ADP-ribosylation is involved in the repair of damaged DNA, the protection exerted by 3-aminobenzamide against the diabetogenic effect of streptozotocin strongly supports the view that this acute effect may be a major consequence of the activation of DNA repair mechanisms in islet cells.

Key words: Experimental diabetes, streptozotocin, poly(ADPribose)synthetase inhibitors, 3-aminobenzamide, nicotinamide, isolated islets, insulin release, immunoreactive insulin.
The $\beta$-cytotoxic effect of streptozotocin (STZ) has been related to the depletion of intracellular nicotinamideadenine dinucleotide (NAD) which occurs shortly after the administration of the drug $[1,2]$. It has been proposed recently [3] that STZ treatment could cause consumption of intracellular NAD stores through activation of poly(ADP-ribose)synthetase, a NAD-degrading enzyme involved in the repair of STZ-induced DNA lesions [4]. Nicotinamide, a precursor of NAD in mammalian cells [5], has been shown to prevent effectively both the fall in NAD content [1] and the cytotoxic effects [6] induced by STZ on $\beta$ cells. It has also been reported that a number of inhibitors of poly(ADP-ribose) synthetase are able to protect isolated islets against the depression of insulin biosynthesis caused by STZ and alloxan [7].

The present study has been performed in order to test the effectiveness of 3-aminobenzamide (3aBA) one of the most potent inhibitors of poly(ADP-ribose)synthetase activity in vitro [8] - in counteracting both the STZ-induced inhibition of glucose-stimulated insulin release by isolated islets and the diabetogenic action of STZ in vivo. For comparison, the protective effect of nicotinamide, a less potent inhibitor of the enzyme but also a precursor of NAD, has also been assessed under the same experimental conditions.

\section{Materials and methods}

\section{Experiments in vitro}

Islets of Langerhans were isolated from the pancreases of SpragueDawley rats ( $250 \mathrm{~g}$ body weight, bred by Morini, S. Polo D'Enza, Italy), by collagenase digestion [9]. After a 40 -min pre-incubation period in modified Krebs-Ringer bicarbonate (KRB) buffer containing $0.5 \%$ bovine serum albumin, N-2-hydroxy-ethylpiperazine-N'-2-ethanesulphonic acid (Hepes) $(10 \mathrm{mmol} / \mathrm{l}, \mathrm{pH} 7.4)$ and glucose $(2.8 \mathrm{mmol} / \mathrm{l})$, groups of seven to ten islets were incubated for $60 \mathrm{~min}$ at $37^{\circ} \mathrm{C}$ in a humidified atmosphere of $5 \% \mathrm{CO}_{2}$ in air, in $1 \mathrm{ml}$ of $\mathrm{KRB}$-Hepes buffer with glucose.

STZ $(0.5 \mathrm{mg} / \mathrm{ml})$, nicotinamide $(2.5 \mathrm{mg} / \mathrm{ml})$ and various concentrations of $3 \mathrm{aBA}$ were dissolved into the incubation medium immediately before addition to the islets. At the end of a $60-\mathrm{min}$ incubation period, the medium was removed for insulin measurement, the islets were washed with buffer and $1 \mathrm{ml}$ of fresh KRB-Hepes buffer, containing glucose $(16.7 \mathrm{mmol} / \mathrm{l})$, was added for a further 60 -min incubation period. In some experiments, freshly-prepared STZ $(0.5 \mathrm{mg} / \mathrm{ml})$ and $3 \mathrm{aBA}$ (at the same concentrations used before) were added again at the beginning of the second incubation period. At the end of this incubation, the medium was again collected for insulin determination. Finally, $1 \mathrm{ml}$ of cold acidified ethanol $(\mathrm{HCl} 0.7 \mathrm{~mol} / \mathrm{l}$ : ethanol, 1 : $3 \mathrm{v} / \mathrm{v}$ ) was added to the islets in order to extract their insulin content. All the buffer changes were carried out under a dissecting microscope to avoid loss of islets.

\section{Experiments in vivo}

Male Sprague-Dawley rats (120-140 g body weight), fasted overnight, were given intraperitoneal injections of either nicotinamide or $3 \mathrm{aBA}$, 


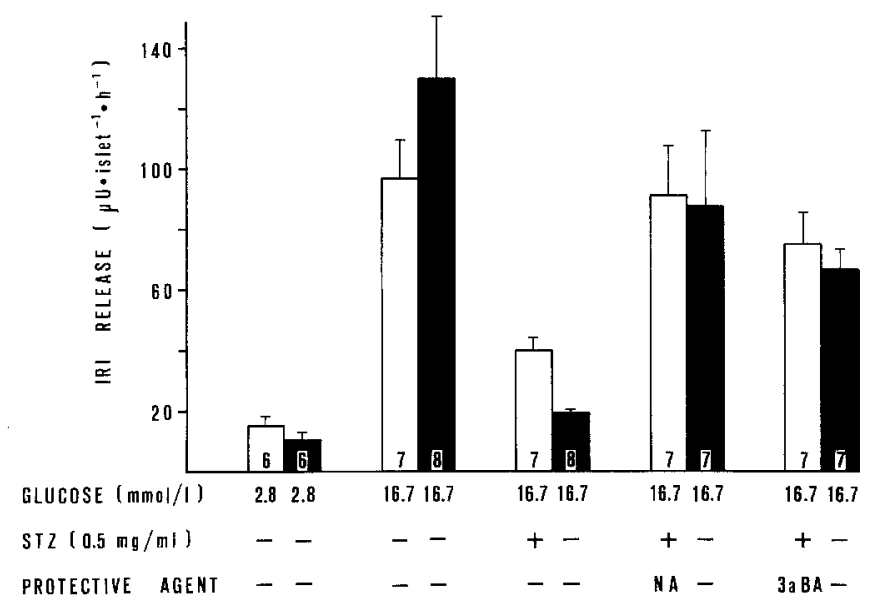

Fig.1. Protective effect of nicotinamide (NA) or 3-aminobenzamide (3aBA) against the STZ-induced inhibition of glucose-stimulated insulin release in freshly isolated rat islets. NA and $3 \mathrm{aBA}$ (at doses of $2.5 \mathrm{mg} / \mathrm{ml}$ and $1.0 \mathrm{mg} / \mathrm{ml}$, respectively) as well as STZ were added to the incubation medium during the first hour of incubation only. Results are given as mean $\pm S E M$ of six to eight observations carried out in two different experiments. The effects of NA or $3 \mathrm{aBA}$ versus STZ alone were highly significant $(p<0.01)$ during both the first and the second hour of incubation (Student's unpaired $t$ test). IRI = immunoreactive insulin. $\square$ 1st hour incubation; $\mathbf{a}$ 2nd hour incubation

Table 1. Effect of 3-aminobenzamide (3aBA) on basal and glucosestimulated insulin release from freshly-isolated rat islets incubated for $60 \mathrm{~min}$ with or without streptozotocin

\begin{tabular}{llc}
\hline Treatment & \multicolumn{2}{l}{ Immunoreactive insulin $\left(\mu \mathrm{U} \cdot\right.$ islet $\left.^{-1} \cdot \mathrm{h}^{-1}\right)$} \\
\cline { 2 - 3 } & Glucose $2.8 \mathrm{mmol} / 1$ & Glucose $16.7 \mathrm{mmol} / \mathbf{1}$ \\
\hline Control & $11.3 \pm 1.2(6)$ & $142.3 \pm 14.4(6)$ \\
STZ $(0.5 \mathrm{mg} / \mathrm{ml})$ & $13.8 \pm 2.5(6)$ & $31.3 \pm 8.2(5)$ \\
3aBA $(1.0 \mathrm{mg} / \mathrm{ml})$ & $17.5 \pm 3.5(5)$ & $96.3 \pm 10.7(5)$ \\
STZ $(0.5 \mathrm{mg} / \mathrm{ml})+$ & $23.3 \pm 9.9(5)$ & $121.5 \pm 18.7(5)$ \\
3aBA $(1.0 \mathrm{mg} / \mathrm{ml})$ & &
\end{tabular}

Results are expressed as mean \pm SEM with the number of observations in parentheses. By the analysis of variance ( $F$ test), the effects of glucose concentration, STZ and the interactions $\mathrm{STZ} \times$ glucose, $\mathrm{STZ} \times 3 \mathrm{aBA}$, glucose $\times 3 \mathrm{aBA}$, STZ $\times$ glucose $\times 3 \mathrm{aBA}$, were highly significant $(p<0.01)$

in doses of 75,150 or $300 \mathrm{mg} / \mathrm{kg}$, dissolved in $0.8 \mathrm{ml}$ of $\mathrm{NaCl}$ solution $(154 \mathrm{mmol} / \mathrm{l})$. Fifteen minutes later, $65 \mathrm{mg} \mathrm{STZ} / \mathrm{kg}$ body weight, freshly dissolved in citrate buffer $(10 \mathrm{mmol} / 1, \mathrm{pH} 4.5)$, were administered iv.

Forty-eight hours later, the rats were decapitated and the blood was collected from the cervical wound in heparinized tubes. The plasma was separated by centrifugation $(900 \mathrm{~g}$ for $10 \mathrm{~min})$ and stored at $-20^{\circ} \mathrm{C}$ until assayed. The pancreas was rapidly removed, weighed and homogenized twice in an acid-ethanol mixture of the same composition as that used for islets (see above). The resulting supernatants were pooled and used for insulin determination.

\section{Assays}

Plasma glucose was assayed by a glucose-oxidase method, using commercial kits (Glucinet, Sclavo, Siena, Italy).

Insulin was measured by radioimmunoassay according to Herbert et al. [10], using rat insulin as standard. The sensitivity and the coefficients of variation of the radioimmunoassay were as follows: detection limit $2.5 \mathrm{mU} / 1$, intra-assay variation $2.7 \%$, inter-assay variation $9.8 \%$.

\section{Chemical reagents}

Streptozotocin and 3-aminobenzamide were purchased from Sigma, St.Louis, Missouri, USA. ${ }^{125}$ I-insulin was kindly provided by Professor R. Navalesi, Institute of Clinical Physiology, University of Pisa. All reagents were of analytical grade.

\section{Expression of results}

Insulin release from isolated islets has been expressed in absolute values $\left(\mu \mathrm{U} \cdot\right.$ islet $\left.^{-1} \cdot \mathrm{h}^{-1}\right)$. In fact, islet insulin content measured at the end of the incubation period(s) was fairly constant between groups of islets, showing that secretory changes were not due to differences in the size of the islets.

\section{Statistical analysis}

Statistical analysis was performed using either analysis of variance (Ftest) or Student's unpaired t-test, as indicated in the legends to Table 1 and the figures.

\section{Results}

\section{Experiments in vitro}

Figure 1 shows that $3 \mathrm{aBA}$ is capable of preserving a normal insulin secretory response to glucose in freshlyisolated islets incubated with STZ. Indeed, the islets exposed to STZ and treated with $3 \mathrm{aBA}$ released an amount of immunoreactive insulin significantly larger than that secreted by the non-protected islets $(p<0.01)$ and similar to that of controls (Fig.1). This protective effect of $3 \mathrm{aBA}$ (used at a concentration of $1.0 \mathrm{mg} / \mathrm{ml}$, i. e. $7.5 \mathrm{mmol} / \mathrm{l}$ ) is slightly smaller than but not significantly different from that exerted by a fully active concentration of nicotinamide $(2.5 \mathrm{mg} / \mathrm{ml}$, i.e. $20.5 \mathrm{mmol} /$ 1) [11]. In both instances, when fresh medium containing glucose $16.7 \mathrm{mmol} / \mathrm{I}$ only (i.e. without STZ or a protective agent) is added for a second hour of incubation, the amount of immunoreactive insulin released by protected islets is still markedly enhanced by comparison with non-protected islets. This amount is nevertheless smaller than that released by control islets (Fig.1, hour 2 of incubation).

In another series of incubation experiments, the effect of $3 \mathrm{aBA}$ on insulin release from isolated islets has been investigated at two different concentrations of glucose, either in presence or absence of STZ (Table 1). The results show that the presence of STZ in the incubation medium does not affect basal insulin release but interferes markedly with stimulation by glucose $(p<0.01)$. The presence of $3 \mathrm{aBA}$ decreases the response to glucose $(p<0.01)$ and counteracts the effect of STZ on glucosestimulated insulin release $(p<0.01)$.

The dose-effect relationship for the action of $3 \mathrm{aBA}$ on glucose-stimulated insulin release from isolated islets incubated in the presence of STZ is shown in Figure 2. During the first $60-\mathrm{min}$ incubation period (Fig. 2A), the release of immunoreactive insulin, markedly reduced by STZ, is restored progressively with in- 


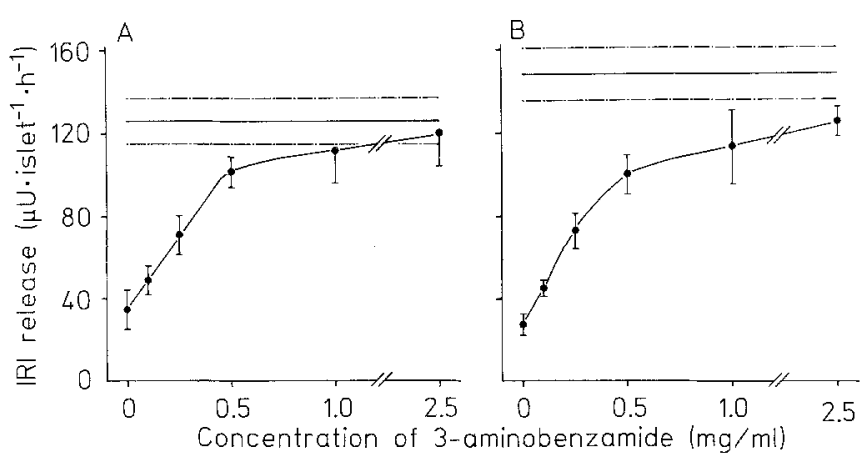

Fig. 2A and B. Dose-effect relationship for action of 3-aminobenzamide on glucose-stimulated insulin release from isolated rat islets incubated in presence of streptozotocin. STZ $(0.5 \mathrm{mg} / \mathrm{ml})$ and increasing concentrations of $3 \mathrm{aBA}(0,0.1,0.25,0.5,1.0$ and $2.5 \mathrm{mg} / \mathrm{ml})$ were present in the incubation medium during both the first (A) and the second (B) hour of incubation (see Materials and methods). The incubations were carried out in the presence of glucose $(16.7 \mathrm{mmol} / 1)$. Results are expressed as mean \pm SEM. The mean (continuous line) \pm SEM (interrupted lines) of insulin release of control islets, incubated in presence of glucose $16.7 \mathrm{mmol} / 1$ without $\mathrm{STZ}$ or $3 \mathrm{aBA}$, is also indicated. A highly significant linear correlation with $3 \mathrm{aBA}$ concentration was found up to the concentration of $1.0 \mathrm{mg} / \mathrm{ml}$ both for the first $(r=0.77, p<0.01)$ and for the second hour of incubation $(r=0.78$, $p<0.01$ ). IRI $=$ immunoreactive insulin
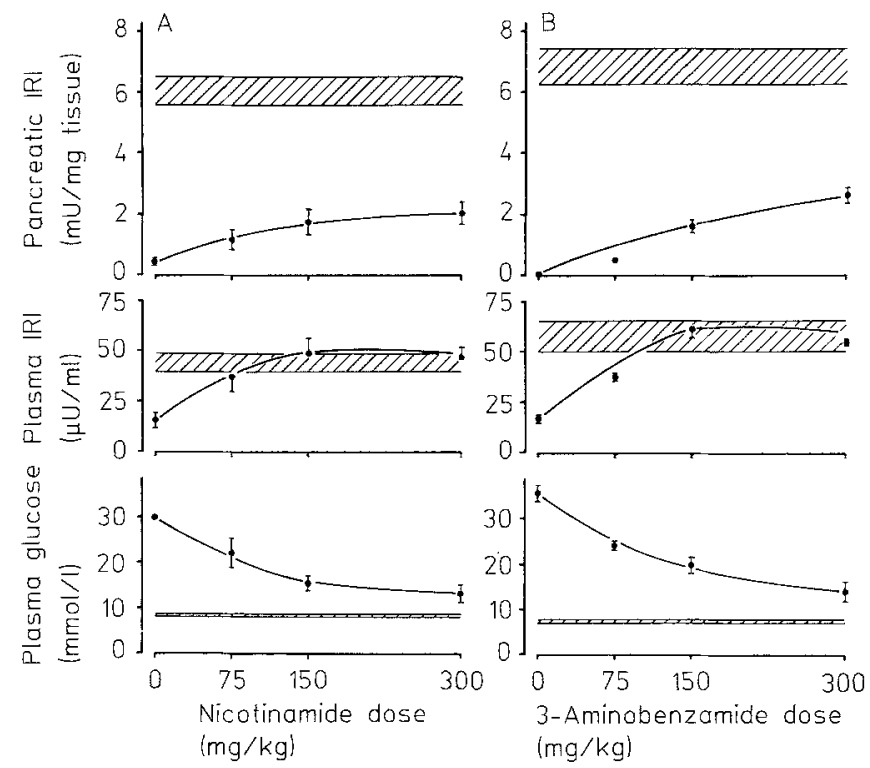

Fig.3A and B. Effects of intraperitoneal administration of nicotinamide (A) and 3-aminobenzamide (B) on plasma glucose and insulin concentrations and on pancreatic insulin content of STZ-treated rats. Either nicotinamide or $3 \mathrm{aBA}$ (at doses of 75,150 and $300 \mathrm{mg} / \mathrm{kg}$ ) was injected intraperitoneally $15 \mathrm{~min}$ before intravenous STZ administration $(65 \mathrm{mg} / \mathrm{kg})$. The animals were killed $48 \mathrm{~h}$ later. Results are expressed as mean \pm SEM of six rats for $\mathbf{A}$ and five rats for $\mathbf{B}$. Shaded areas refer to the mean $\pm S E M$ of control rats which only received the vehicles of injected substances. IRI $=$ immunoreactive insulin

creasing concentrations of $3 \mathrm{aBA}$ added to the medium. The insulin release shows a highly significant linear correlation $(p<0.01)$ with the concentrations of $3 \mathrm{aBA}$, at least up to that of $1.0 \mathrm{mg} / \mathrm{ml}$. A similar curve is observed for the subsequent hour of incubation, when STZ and various doses of $3 \mathrm{aBA}$ are added again to the fresh incubation buffer (Fig.2B). The protective effect of $3 \mathrm{aBA}$ is already apparent at the lowest concentration used $(0.1 \mathrm{mg} / \mathrm{ml})$. Also in these experiments, glucosestimulated insulin release from the islets incubated in the presence of $3 \mathrm{aBA}$, without STZ, was slightly lower than that from control islets (not shown).

\section{Experiments in vivo}

The effects of the administration of various doses of nicotinamide (panel A) and 3aBA (panel B) on plasma glucose and immunoreactive insulin levels as well as on pancreatic insulin content of STZ-treated rats are shown in Figure 3. It is apparent that prevention of STZ-induced changes improves with increasing dosage of each protective agent in a similar fashion. Indeed, the administration of either nicotinamide or $3 \mathrm{aBA}$ at a dose of $300 \mathrm{mg} / \mathrm{kg}$ to STZ-treated rats, results in marked reduction of hyperglycaemia at $48 \mathrm{~h}$, prevention of the decrease of insulin plasma levels and significant limitation of the dramatic fall in pancreatic hormone content. Similarly at smaller doses, the protective action of $3 \mathrm{aBA}$ is in general comparable to that of nicotinamide.

\section{Discussion}

The results of the present study indicate that an inhibitor of poly(ADP-ribose)synthetase such as 3-aminobenzamide is effective in preventing the inhibition of glucose-stimulated insulin release induced by STZ in vitro, as well as in protecting the rats from the diabetogenic effect of the drug administered in vivo.

This protective action of 3-aminobenzamide appears to be quantitatively comparable to that of nicotinamide, an agent capable of preventing the effects of STZ. Indeed, both agents, when administered in vivo 15 min before STZ, appear to be effective at similar molar concentrations (nicotinamide and $3 \mathrm{aBA}$ have similar molecular weights: 122 and 136, respectively). Furthermore, the two substances exhibit similar dose-effect relationships in spite of the very different inhibitory effects on the poly(ADP-ribose)synthetase enzyme activity in vitro (3aBA being about 18 times more potent than nicotinamide) [7]. This discrepancy cannot be attributed to a marked difference in the kinetics of the two substances, since it can also be inferred from the results of the experiments in vitro. Perhaps the two drugs exert their protective action by different mechanisms. In this respect, it should be mentioned that $3 \mathrm{aBA}(300 \mathrm{mg} / \mathrm{kg}$ body weight) is still effective when injected intraperitoneally $2 \mathrm{~h}$ after STZ administration (unpublished data), when nicotinamide is no longer effective [12]. Therefore, we suggest that inhibition of poly(ADP-ribose)synthetase activity is a major, but not unique, mechanism by which islet cells can be protected against the acute toxic effect of STZ. Stimulation of NAD biosynthesis by nicotinamide may also make a significant 
contribution to the protective action exerted by this vitamin.

It is also interesting to note that neither $3 \mathrm{aBA}$ nor nicotinamide, even at the highest dosage used in this study, is able to give full protection in vivo. In particular, the STZ-induced decrease of pancreatic insulin content, a reliable index of the damage to $\beta$ cells [13], is only moderately counteracted by the administration of either protective agent. Therefore, it appears that these protective agents can effectively preserve the endocrine function of the whole pancreas from the insult of STZ, but cannot prevent impairment by the drug of a significant proportion of islet cells. This damage might cause a decrease in the functional endocrine reserve of the animal or lead to the development of islet cell tumours [14]. It is not yet known whether higher doses of these protective agents are able to prevent completely the fall of pancreatic insulin content in STZ-treated rats.

As regards the experiments in vitro, from the comparison of the data referring to the second 60 -min incubation periods, it is apparent that in presence of STZ and $3 \mathrm{aBA} 1.0 \mathrm{mg} / \mathrm{ml}$ during the second as well as the first hour of incubation, glucose-stimulated insulin release from isolated islets rises up to $76 \%$ of that of control islets (Fig. 2B), whereas when 3aBA (and STZ) is not added during the second hour IRI release is $51 \%$ of that of control islets (Fig.1). Therefore, the protection appears to be more effective the longer $3 \mathrm{aBA}$ is present during the incubation period.

In conclusion, our results give substantial support to Okamoto's suggestion [3] that STZ cytotoxicity is secondary to the activation of DNA repair synthesis provoked by STZ-induced lesions of DNA strands. It has already been reported that poly(ADP-ribose)synthetase inhibitors prevent the STZ-induced depression in islet proinsulin synthesis $[7,15]$ as well as the reduction of NAD content and the impairment of islet respiration rate [16]. Here, we have provided evidence that poly(ADP-ribose)synthetase inhibitors which are not precursors of NAD, such as $3 \mathrm{aBA}$, are also able to neutralize the final effects of STZ on pancreatic endocrine function in vitro and in vivo.

Acknowledgements. This work was supported in part by grants from Ministero della Pubblica Istruzione and from CNR (gruppo di Endocrinologia). The skillful technical assistance of Mr. E. Madrigali is gratefully acknowledged.

\section{References}

1. Ho CK, Hashim SA (1972) Pyridine nucleotide depletion in pancreatic islets associated with streptozotocin-induced diabetes. Diabetes 21: 789-793
2. Hinz M, Katsilambros N, Maier V, Schatz H, Pfeiffer EF (1973) Significance of streptozotocin-induced nicotinamide-adeninedinucleotide (NAD) degradation in mouse pancreatic islets. FEBS Lett 30:225-228

3. Okamoto H (1981) Regulation of proinsulin synthesis in pancreatic islets, and a new aspect to insulin-dependent diabetes. Mol Cell Biochem 37: 43-61

4. Yamamoto H, Uchigata Y, Okamoto H (1981) Streptozotocin and alloxan induce DNA strand breaks and poly(ADP-ribose)synthetase in pancreatic islets. Nature 294: 284-286

5. Ichiyama A, Nakamura S, Nishizuka Y (1967) Studies on the biosynthesis of nicotinamide adenine dinucleotide (NAD) in mammals and its regulatory mechanism. Part II. Arzneimittelforsch 17: $1525-1530$

6. Gunnarsson R, Berne C, Hellerström C (1974) Cytotoxic effects of streptozotocin and N-nitrosomethylurea on the pancreatic B cells with special regard to the role of nicotinamide-adenine dinucleotide. Biochem J 140: 487-494

7. Uchigata Y, Yamamoto H, Kawamura A, Okamoto H (1982) Protection by superoxide dismutase, catalase, and poly(ADP-ribose) synthetase inhibitors against alloxan- and streptozotocin-induced islet DNA strand breaks and against the inhibition of proinsulin synthesis. J Biol Chem 257: 6084-6088

8. Purnell MR, Whish WJD (1980) Novel inhibitors of poly(ADP-ribose)synthetase. Biochem J 185: 775-777

9. Lacy PE, Kostianovky M (1967) Method for the isolation of intact islets of Langerhans from rat pancreas. Diabetes 16: 35-39

10. Herbert V, Lau K-S, Gottlieb CW, Bleicher SJ (1965) Coated charcoal immunoassay of insulin. J Clin Endocr 25: 1375-1384

11. Golden P, Baird L, Malaisse WJ, Malaisse-Lagae F, Walker MM (1971) Effect of streptozotocin on glucose-induced insulin secretion by isolated islets of Langerhans. Diabetes 20: 513-518

12. Stauffacher W, Burr I, Gutzeit A, Beaven D, Veleminsky J, Renold AE (1970) Streptozotocin diabetes: time course of irreversible Bcell damage; further observations on prevention by nicotinamide. Proc Soc Exp Biol Med 133: 194-200

13. Masiello P, De Paoli AA, Bergamini E (1979) Influence of age on the sensitivity of the rat to streptozotocin. Hormone Res 11: 262-274

14. Masiello P, Wollheim CB, Blondel B, Renold AE (1983) Studies in vivo and in vitro on chemically-induced primary islet cell tumours and non-tumour endocrine pancreatic tissue. Diabetologia 24: $30-37$

15. Uchigata $Y$, Yamamoto $H$, Nagai H, Okamoto H (1983) Effect of poly(ADP-ribose)synthetase inhibitor administration to rats before and after injection of alloxan and streptozotocin on islet proinsulin synthesis. Diabetes $32: 316-318$

16. Sandler S, Welsh M, Andersson A (1983) Streptozotocin-induced impairment of islet B-cell metabolism and its prevention by a hydroxyl radical scavenger and inhibitors of poly(ADP-ribose)synthetase. Acta Pharmacol Toxicol 53: 392-400

Received: 21 January 1985

and in revised form: 19 June 1985

Dr. Pellegrino Masiello

Istituto di Patologia Generale

Scuola Medica

Via Roma, 55

I-56100 Pisa

Italy 